\title{
Construction Safety on Scaffolding: Building Information Modeling (BIM) and Safety Management - A Systematic Review
}

\author{
Mário Rebelo ${ }^{1}$, Francisco Silveira ${ }^{2}$, Elżbieta Czarnocka ${ }^{3}$, Krzysztof \\ Czarnocki $^{4}$ \\ ${ }^{1}$ Doctoral Program in Occupational Safety and Health, Faculty of Engineering, University of \\ Porto, Porto, Portugal (up201711584@fe.up.pt) ORCID 0000-0003-1878-1143; 2Doctoral \\ Program in Occupational Safety and Health, Faculty of Engineering, University of Porto, Porto, \\ Portugal (up200501168@fe.up.pt) ORCID 0000-0002-4179-5722; ${ }^{3}$ Faculty of Management, \\ Lublin University of Technology, Nadbystrzycka 38 D 20-618 LUBLIN, Poland \\ (e.czarnocka@pollub.pl) ORCID 0000-0003-1706-7861; ${ }^{4}$ Faculty of Management, Lublin \\ University of Technology, Nadbystrzycka 38 D 20-618 LUBLIN, Poland (k.czarnocki@pollub.pl) \\ ORCID 0000-0001-8790-9417
}

\begin{abstract}
The construction industry is one of the most hazardous industries, with a high number of working injuries and fatalities. A special issue for occupational accidents in the construction industry is the use of scaffolds, which is usually attributed to falls from height. Research and practice have demonstrated that decisions made upstream from the construction site can influence construction worker safety. Therefore, it is crucial to assess the risk levels for different construction stages on scaffolding, with various work trades, aiming to prevent the occurrence of fall accidents. The use of new techniques and methodologies, such as Building Information Modeling (BIM), is of major importance. The growing implementation of BIM in Architecture, Engineering and Construction (AEC) is changing the way safety can be approached.

This study reviews the existing literature about BIM and construction safety on scaffolding, to explore useful findings and detect knowledge gaps for future research. Despite the enormous evolution of research and technological innovations based on BIM for construction safety, there is still a flagrant lack of knowledge and solutions for identifying hazards related to construction on scaffolding.
\end{abstract}

Author Keywords. Construction, Safety, BIM, Building Information Modeling, Scaffold, Scaffolding.

Type: Review Article

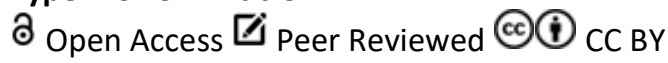

\section{Introduction}

Globally, the construction industry is an inescapable sector of the economy at the international level, employing a significant percentage of active workers. However, this industry is classified among the economy sectors that present high occupational risks and an unsatisfactory level of occupational safety. When comparing workplace accidents in the European Union (EU) over a period from 2008 to 2016, the construction sector presents the highest number of fatal accidents (EUROSTAT 2016). Most serious accidents occurred on scaffolding or on scaffolding sites. Several factors contribute to these statistics (Hide et al. 2003; Gibb et al. 2006) and result in many safety hazards which may arise at any given stage of the construction process (Gibb et al. 2006; Qi et al. 2014). In recent years, different technologies and construction methods have been developed with the aim of providing new ways of enhancing safety management throughout the whole project lifecycle (MartínezAires, López-Alonso, and Martínez-Rojas 2018). The objective is to improve rather than replace 
management-driven safety (Teizer et al. 2010), identifying, for example, human errors and deal with them quickly to prevent construction accidents, as well as predicting, planning and controlling the schedule. The different studies have highlighted the possibility of linking the Computer-Aided Design (CAD) and planning process (Cherneff, Logcher, and Sriram 1991) as an alternative to mock-ups, and have looked at the opportunities that are available in the near-term data (Tatum, Byrum, and Rourke 1994). The most important shift in information and communication technology (ICT) for construction industry was the Building Information Modeling (BIM), which proliferation was occurred in industrial and academic contexts as a new CAD paradigm (Succar 2009). The international standards refer to BIM as a "shared digital representation of physical and functional characteristics of any built object which forms a reliable basis for decisions" (ISO 2010). Some special tools of design, engineering and architecture professions have recently joined the basic functionalities, like scheduling, structural analysis, energy analysis, progress tracking or jobsite safety (Becerik-Gerber et al. 2012). BIM is mainly concentrated on the design, preplanning, construction and integrated project delivery of infrastructure and buildings. However, in recent years, researchers have shifted their focus from earlier stages of life cycle to the end-of-life considerations such as refurbishment, maintenance, demolition (Becerik-Gerber et al. 2012; Akbarnezhad, Ong, and Chandra 2014; Eastman et al. 2011), particularly in complex structures.

Currently, as reflected in the literature, there are many proposals that use BIM technology to assist with different construction management tasks (Martínez-Aires, López-Alonso, and Martínez-Rojas 2018). Despite this, the construction industry is a sector which is typically slow to accept changes, therefor the adoption of BIM has only just begun to increase around the world in recent years (Silva et al. 2016). Using BIM, conventional three-dimensional (3D) or four-dimensional (4D) models become $n \mathrm{D}$ model that incorporates multiple aspects of design information required at each stage of the lifecycle of a project (Ding, Zhou, and Akinci 2014; Shou et al. 2015).

In the early 1990s, Mattila and colleagues predicted that there was a need to study the connections between good management, in general, and safety (Mattila, Hyttinen, and Rantanen 1994). Since then, many studies related to safety management have been developed and research progresses in BIM and its applications, such as occupational safety, have been achieved (Martínez-Aires, López-Alonso, and Martínez-Rojas 2018).

Scaffolding is a temporary structure which serves as support for operations of work crews and materials aside under-constructing or existing facilities. Well-designed and well-established, scaffolding is indispensable for the activities to progress safely, smoothly, efficiently and successfully (Wang et al. 2016).

The main objective of this paper is to review existing proposals in this field of research, aiming to identify the applications and evolution of BIM for safety management in the subdomain of construction safety on scaffolding. As the author will demonstrate, there are many outstanding proposals for construction safety in general, nevertheless, only a very few number for construction safety on scaffolding. Additionally, the current situation will be analyzed and further suggestions will be made with the aim of fostering and directing future research on BIM concerning the management of construction safety on scaffolding.

\section{Background of the Research Domain}

Several studies show that BIM could greatly benefit the architecture, engineering and construction (AEC) industry as a tool that contributes to safety management, e.g. through scheduling, clash detection, construction progress tracking, design consistency and 
visualization, data integration, cost estimations, implementation of lean construction or improved team member collaboration, etc. (Martínez-Aires, López-Alonso, and MartínezRojas 2018).

A recent review regarding safety studies from 1978 to 2013 (1628 analyzed documents) show that BIM is not a unique tool for this purpose. The study identifies 21 types of applied innovative technologies and only 6 documents related to BIM applications (Zhou et al. 2015). In a recent survey (Suermann and Issa 2009) defined questions to collect data regarding perceptions about the effects of BIM on commonly accepted construction key performance indicators (KPIs), which were defined by Cox and colleagues: quality control, on time completion, cost, safety, \$/unit, units/manhour (Cox, Issa, and Ahrens 2003). The results indicated that some respondents did not realize the advantages for safety or for lost manhours in construction projects. Ding, Zhou, and Akinci (2014) conducted a study that shows the percentages of published works on BIM from the perspective of project management, with $7 \%$ related to safety management and $17 \%$ related to schedule management.

\subsection{Planning}

From collected data (Council Directive 92/57/EEC 1992), it was possible to stablish that unsatisfactory architectural and/or organizational options or poor project planning at the project preparation stage have played a role in more than half of the occupational accidents occurring on construction sites in the EU. Effective safety planning contributes to the prevention of accidents and illness of site personnel. Proper planning for safety plays has an important role in reducing unnecessary costs and delays (Saurin, Formoso, and Guimarães 2004; Sulankivi, Mäkelä, and Kiviniemi, 2009; Bansal 2011). The identification of overlapping activities is also a concern since the workspace for those activities may be conflicting and accidents can occur (Moon, Dawood, and Kang 2014).

In 1994, the need to consider a schedule for the overseeing of accidents and their integration in graphic programs was also stated (Euler 1994), and was developed a framework for a computerized health and safety knowledge-intensive system that has since been implemented and integrated with the current critical path method (CPM) scheduling software (Kartam 1997).

As stated by Volk and colleagues, the applied BIM functionalities can be classified into numerous subclasses, such as localization of building components, subcontractor and supplier integration, life cycle assessment (LCA), monitoring, sustainability, performance measurement, facility management (FM), operations and maintenance (O\&M), risk scenario planning, jobsite safety, emergency management, space management, and scheduling (4D) (Volk, Stengel, and Schultmann 2014). The term 4D was used by (McKinney et al. 1996), being defined as $3 D$ plus time (schedule). In 1998, McKinney strongly suggested that the construction perspective was often neglected because an important dimension for construction-time was missing and stated the necessary efforts to develop $4 \mathrm{D}$ tools that generate $4 D+x$ models, which more realistically represent the construction process (McKinney and Fischer 1998). Guo and colleagues concluded that 4D models are a useful alternative to project scheduling tools like CPM (Guo 2001; Koo and Fischer 2000).

Since 2005, publications have been using the term BIM as we know it today (Tse, Wong, and Wong 2005), referring the software as BIM, virtual building, parametric modeling, or modelbased design. As previously mentioned, many authors have defined $4 \mathrm{D}$ as $3 \mathrm{D}$ plus schedule from the beginning of the BIM studies, such as Hu and Zhang (2011) up to, more recently, (Zhang, Boukamp, and Teizer 2015; Zhou et al. 2015). Moreover, the concept 4D is not only 
related to other concepts, but also to BIM, such as its utility on projects that involve many cobuilders, and is reflected by Trebbe, Hartmann, and Dorée (2015). Therefore, the potential of 4D CAD models has been widely acknowledged to avoid costly on-site improvisation, providing tools to better anticipate conflicts in the planning phase (Martínez-Aires, López-Alonso, and Martínez-Rojas 2018).

More recent digital technologies have led to the development of new construction process planning techniques, to allow users to establish more effective construction plans by anticipating project results, such as Genetic Algorithm, Geographic Information System (GIS) and Case-Based Reasoning (CBR) (Martínez-Aires, López-Alonso, and Martínez-Rojas 2018). GIS is a framework for gathering, managing and analyzing data. It integrates many types of data, analyzes spatial location and organizes information layers into visualizations using maps and 3D scenes. CBR is a process of solving new problems based on the solutions of similar past problems.

\subsection{Innovative technology applications}

The most widespread technologies applied to construction safety are: Virtual Reality, CAD 4D, BIM, etc., being widely used as tools designed for the prevention of on-site risks and safe delivery of projects (Zhou, Whyte, and Sacks 2012). Other technologies with these purposes were used before the development and generalization of BIM. Yamazaki (1992) and later, in 1999, Jung and colleagues associated the use of Computer Integrated Construction to maximize the integrated use of information systems throughout the project's entire lifecycle for different functions, including security (Jung and Gibson Jr 1999). Among other, Seo and colleagues reviewed other research studies concerning Health and Safety, monitoring and identifying 22 records from 2007 to 2013 (Seo et al. 2015).

Simultaneously, BIM was also used to modify schedules to minimize spatial conflicts (Akinci, Fischer, and Kunz 2002; Clayton, Warden, and Parker 2002; Dawood et al. 2003; Waly and Thabet 2003). In other cases, it was used to permit management for construction projects (Chau, Anson, and De Saram 2005; Chau, Anson, and Zhang 2005; Kang, Anderson, and Clayton 2007; Wang et al. 2004).

More recently, several researchers combined BIM with different technologies, such as location tracking, Augmented Reality (AR) and game technologies (Park and Kim 2013), Virtual Prototyping (VP) (Wang, Liu, and Chou 2006; Guo, Li, and Li 2013); RFID (or WSN in a broader scope) (Motamedi and Hammad 2009). In addition, different research studies combined the schedule, BIM and simulation as a tool capable to predict risks, aiming to minimize conflicts at the workplace, as well as to be used as an active schedule management tool (Kim and Teizer 2014; Moon, Dawood, and Kang 2014; Moon et al. 2014).

\subsection{Collaboration and communication}

Shen and colleagues considered that these technologies can provide a consistent set of solutions to support the collaborative creation, management, dissemination and use of information throughout the product and project lifecycle, playing an important role in improving productivity and efficiency in the construction industry (Shen et al. 2010). Unfortunately, in this sector one of the main barriers is the lack of communication throughout the project, and it is a reality that data concerning safety on a construction site are rarely shared with all other interested professionals (Martínez-Aires, López-Alonso, and MartínezRojas 2018). New research directions on construction safety and digital design could allow, for example, to focus on technologies that enable constructors to share their knowledge with designers (Zhou, Whyte, and Sacks 2012). 
A new concept has come, with a short time development, over the last decade, known as Prevention through Design (PtD) and deserving a wide acceptance, as it has proved to be an extremely effective tool in eliminating risks during the execution phase of a project (Hinze and Wiegand 1992; Gambatese and Hinze 1999; Gibb et al. 2006; Frijters and Swuste 2008; Martínez Aires, Rubio Gámez, and Gibb 2010). In addition, several researchers have shown how BIM is useful for improving the implementation of PtD (Melzner et al. 2013; Zhang et al. 2013; Zhang, Boukamp, and Teizer 2015; Chavada, Dawood, and Kassem 2012; Qi et al. 2014). BIM's application in the design and final stages of the project was shown to be linked to safety management and the prevention of accidents, and its application from the early stages of project's lifecycle is linked to a decrease in the accident rate (Gibb et al. 2006; Martínez Aires, Rubio Gámez, and Gibb 2010).

From the combination of the results obtained using BIM throughout the lifecycle of the project with the team member collaboration aspects related to its adoption, result the most positive financial impacts ( $G$ u and London 2010; Eadie et al. 2013). BIM is a tool used to share knowledge, provide information and provide a solid basis for decision-making throughout the project's lifecycle (Martínez-Aires, López-Alonso, and Martínez-Rojas 2018). Thus, Ding, Zhou, and Akinci (2014) established the use of BIM from design to demolition, although Shou and colleagues highlight the fact that the use of BIM is mainly related to the construction stage (Shou et al. 2015). In addition, it can also be shown that BIM is becoming increasingly useful due to its upstream use, in the pre-construction phase, as a tool that supports collaboration (Succar 2009; Succar and Kassem 2015; Wang and Chong 2015).

\section{Materials and Methods}

This section outlines the systematic review as a methodological approach to explore useful findings in the existing literature about construction safety and BIM, and to identify the lack of knowledge for future research. A systematic review is used for identifying, selecting and appraising all the literature of a certain agreed level of quality that is relevant to a research question (Booth, Sutton, and Papaioannou 2016). This systematic review is conducted in accordance with the Preferred Reporting Items for Systematic Reviews and Meta-Analyses (PRISMA) guidelines (Liberati et al. 2009).

The databases sources used were Web of Science, Science Direct, Scopus and IEEE. The period studied ranges from 2008 to 2018 and the search was carried out using the "Title/Abstract/Keyword" field of the databases. The full search is "Title/Abstract/Keyword Construction AND BIM AND safety AND (scaffold OR scaffolding)" or "Title/Abstract/Keyword Construction AND "building Information modeling" AND safety AND (scaffold OR scaffolding)". There were 13 documents identified through a database search and, after removing duplicates, this number was reduced to a total of 9 documents. Furthermore, 7 documents under search criteria "Title/Abstract/Keyword Construction, BIM and Management" were included. After removing duplicates, this number was reduced to a total of 2 documents. The topic of Safety was discussed in all of them.

Of the total number of documents $(n=11), 4$ were conference papers and 7 were articles. The systematic review only focused on 5 articles and 2 conference papers, because 2 articles and 2 conference papers are not fully available.

Figure 1 illustrates PRISMA flow diagram, where the number of documents after applying the selection criterion is shown in each stage. Finally, as can be seen in the figure, 11 documents were reviewed. 


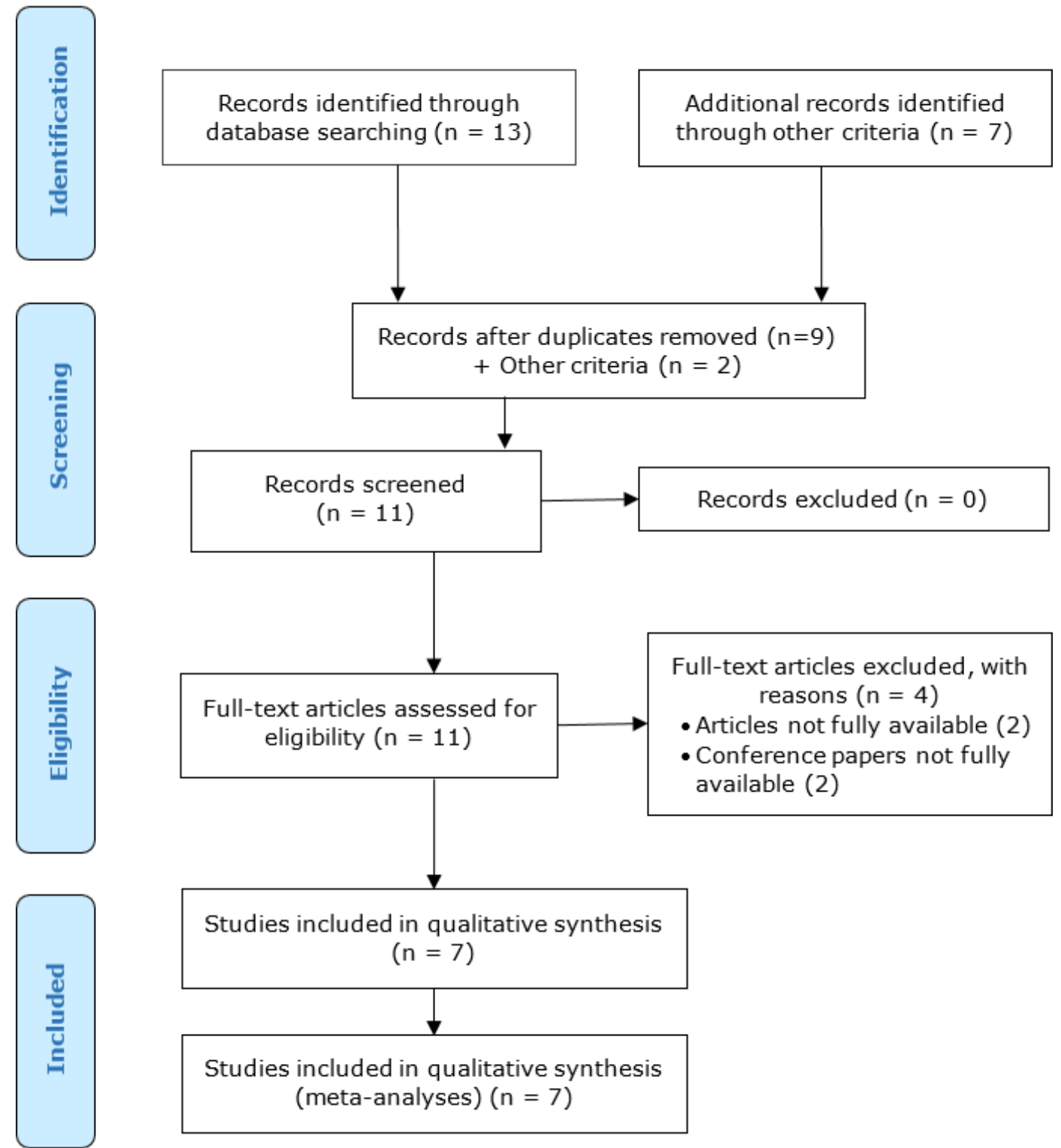

Figure 1: Flowchart of systematic review process (PRISMA flow diagram)

The publications were found on the considered databases which deal with BIM or Building Information Modeling on the area of Engineering linked to Construction-Architects, Engineers, Contractors (AEC).

Considering the results presented in Section 2, five key areas have been identified, which define BIM use as a safety management tool: i) construction or safety management (SM), ii) 4D schedule and planning (SP), iii) visualization/simulation (VS), iv) collaboration and communication (CC), and v) identifying hazards $(\mathrm{IH})$. The 7 articles have been analyzed using the following protocol: (1) work title; (2) year of publication; (3) magazine title; (4) country; (5) project phase identification where BIM is used: design, construction, maintenance, namely, during the project's whole lifecycle; (6) highlights identification; (7) innovative technology use identification and other differentiating aspects.

\section{Results and Discussion}

\subsection{Publishing framework}

This section results from the above presented steps (1) to (4), which allow to establish the publishing framework of the texts being analyzed. 
Table 1 shows the number of publications regarding construction safety on scaffolding and BIM published by authors' country/region. This information is in line with the research carried out by Porwal, which proves that BIM implementation is still a challenge for the North American construction industry (Porwal and Hewage 2013). Succar (2009) shows a nonexhaustive list of publicly-available guides, reports and models relating to BIM, which shows that the USA have the greatest number of Construction Safety and BIM research articles published since 2009.

\begin{tabular}{cc}
\hline Country/Territory & Authors \\
\hline United States & 13 \\
Australia* & 8 \\
China & 5 \\
Taiwan & 5 \\
Canada & 1 \\
Germany & 1 \\
Puerto Rico & 1 \\
South Korea & 1 \\
\hline *Australasian Joint Research Centre for \\
Building Information Modelling, Curtin \\
University, Perth, Australia
\end{tabular}

Table 1: Number of publications regarding construction safety on scaffolding and BIM published by authors' country/region

Table 2 shows the number of publications per source.

\begin{tabular}{cc}
\hline Source & Documents \\
\hline Automation in Construction & 13 \\
Journal of Construction Engineering and Management - ASCE & 8 \\
IEEE Proceedings & 5 \\
Advances in Engineering Education & 1 \\
13th International Conference, CDVE 2016, Proceeding Book & 1 \\
Advanced Engineering Informatics & 1 \\
\hline
\end{tabular}

Table 2: Number of documents regarding construction safety and BIM by source

Figure 2 shows the distribution of articles linking BIM and construction safety per year, related with this study.

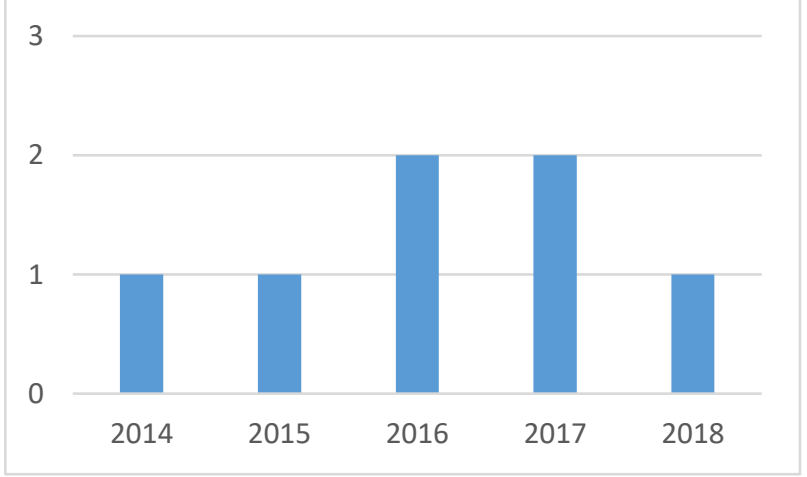

Figure 2: Annual distribution of articles

\subsection{Highlights of comparative review}

The results from steps (5) to (7) of the analysis method are detailed in this section, so the articles were arranged in Table 3, with the objective of organizing construction safety and BIM content proposed by the author, identifying the key areas addressed as well as certain distinguishing features. The first column presents each article by author and year of publication. The next five present the five key areas established for this study: Construction or Safety Management (SM), 4D Schedule and Planning (SP), Visualization/Simulation (VS), 
Collaboration and Communication (CC), and Identifying Hazards (IH). The seventh column gathers other distinguishing features from the research published in the articles.

\begin{tabular}{|c|c|c|c|c|c|c|}
\hline Source & SM & VS & IH & SP & $\mathbf{C C}$ & $\begin{array}{l}\text { Other } \\
\end{array}$ \\
\hline $\begin{array}{c}\text { Clevenger, Del } \\
\text { Puerto, and Glick } \\
\text { (2015) }\end{array}$ & Yes & & & & Yes & $\begin{array}{l}\text { Safety training within construction education. OSHA } \\
\text { requirements for scaffolds. }\end{array}$ \\
\hline Wang et al. (2016) & & Yes & & & Yes & Mobile application. Requirement analysis \\
\hline Jin et al. (2017) & Yes & Yes & & & Yes & R\&D. VC. Scaffolding placement requirements. \\
\hline $\begin{array}{l}\text { Kim and Teizer } \\
\text { (2014) }\end{array}$ & Yes & Yes & & Yes & & $\begin{array}{c}\text { Temporary facilities. Scaffolding systems. Accident } \\
\text { cases. Retrieval system. }\end{array}$ \\
\hline $\begin{array}{l}\text { Kim, Cho, and Kim } \\
\text { (2018) }\end{array}$ & Yes & Yes & & & & CPM \\
\hline $\begin{array}{l}\text { Kim, Cho, and Zhang } \\
\text { (2016) }\end{array}$ & Yes & & Yes & Yes & Yes & R\&D. Temporary structures. Scaffolds. PtD. \\
\hline Chi et al. (2017) & Yes & Yes & & Yes & & $\begin{array}{l}\text { AR. VR. Progress and productivity monitoring } \\
\text { strategies for scaffolding tasks. }\end{array}$ \\
\hline \multicolumn{7}{|l|}{ Acronym } \\
\hline$A R$ & & & & & & Augmented Reality \\
\hline BIM & & & & & & Iding Information Model \\
\hline $\mathrm{CC}$ & & & & & Collak & oration and Communication \\
\hline CPM & & & & & & Critical Path Method \\
\hline $\mathrm{IH}$ & & & & & & Identifying Hazards \\
\hline PtD & & & & & & evention through Design \\
\hline$R \& D$ & & & & & & earch and Development \\
\hline SM & & & & & Constr & Iction or Safety Management \\
\hline SP & & & & & & Schedule and Planning \\
\hline VC & & & & & & Virtual Construction \\
\hline VR & & & & & & Virtual Reality \\
\hline VS & & & & & & isualization/Simulation \\
\hline
\end{tabular}

Table 3: Key areas Comparative Review

Figure 3 gives a summary of the results in Table 3, which presents the percentages of articles that addressed the five defined key areas.

$85.71 \%$ of studies have safety management as their focus, followed by $71.43 \%$ which refer to BIM use for visualization or simulation. The identification of hazards is a key objective, nevertheless is present in just $14.29 \%$ of the documents. Scaffolds are among all the studied systems. BIM is used as a tool to enable collaboration and communication; these topics are today's active research topics and will still be active in the next 5-10 years (Shen et al. 2010). In this becoming, safety training has resulted the objective of a research study regarding the use of BIM to improve workers' education or training (Clevenger, Del Puerto, and Glick 2015).

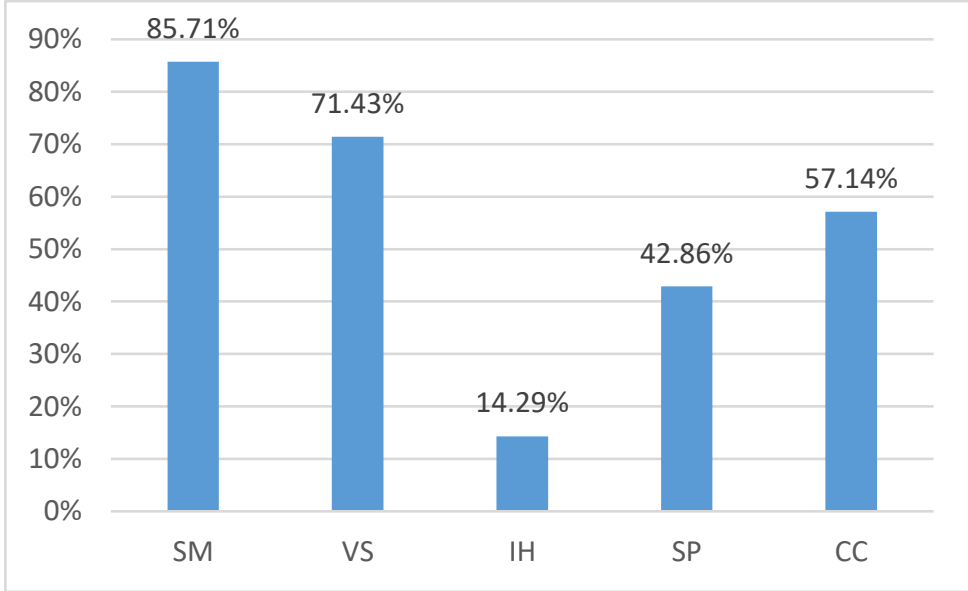

Figure 3: Key areas and percentage of articles studied 
On the other hand, Figure 4 shows the percentage of publications regarding BIM a project lifecycle viewpoint. $57.14 \%$ of the projects use BIM in the design and construction phase. Nevertheless, $28.58 \%$ of the studies include just the construction stages of the projects, and $14.28 \%$ the lifecycle. This demonstrates the usefulness of BIM in terms of prevention of accidents through design (Melzner et al. 2013; Qi et al. 2014; Zhang et al. 2013; Zhang, Boukamp, and Teizer 2015). None of the analyzed articles studies the totality of the life stages of the construction, resulting in $0 \%$ of the lifecycle.

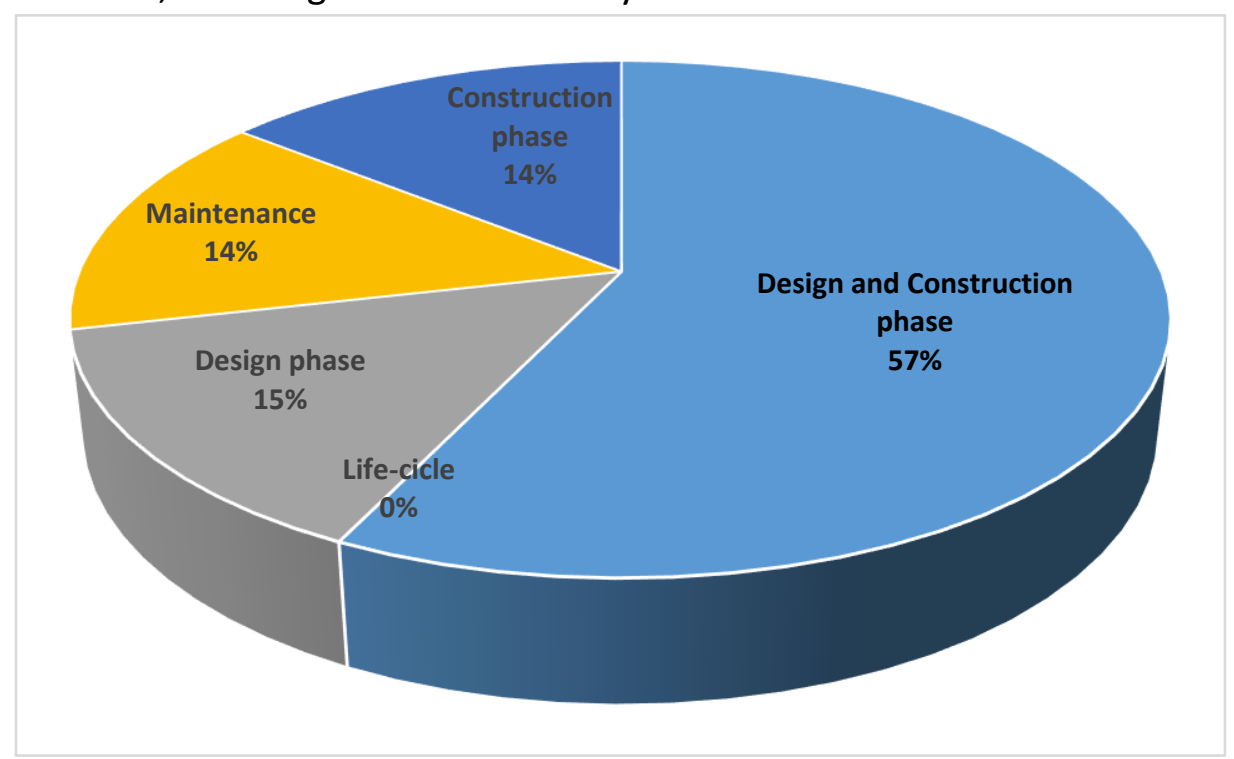

Figure 4: Percentage of articles studied from the viewpoint of project life cycle

\section{Conclusions}

BIM and interoperability of software have emerged with substantial improvements in recent years, permitting development of digital collaboration. However, to achieve potential benefits, is necessary to get through the many difficulties of BIM adoption.

The key benefits of BIM adoption are summarized in the following:

- Sustainable BIM adoption will improve project communication, allowing stakeholders to collaborate more effectively and more accurately, diminishing the design errors and reworks pertaining to the construction activities.

- $\quad$ BIM is by nature multidisciplinary. Therefore, BIM brings project members together, creating constant communication, increasing the integration of design and construction phase and decreasing the hazardous construction activities on scaffolding associated with safety issues.

- BIM-model can be used as online databases throughout the life of the building, communicating information to all project members involved.

The key challenges of BIM adoption are summarized in the following:

- BIM is a socio-technical system. Therefore, sustainable BIM adoption requires an integrated approach, combining technical structures and social practices.

- Adoption of BIM comes with a learning curve. Consequently, sustainable BIM adoption requires extensive preparation and training of employees.

- BIM collaboration between organizations (and across national borders) appears problematic. Therefore, there is a need for common standards and documented procedures. 
- Interoperability between BIM tools appears problematic. Consequently, shared regulations and standardized exchange formats are needed.

- BIM adoption leads to organizational change. For example, changes in work practices and interpersonal dynamics. For changes to be adopted, managers and leaders must engage.

BIM provides a solid visual understanding of a site and the working conditions before the initiation of the construction phase, as well as facilitating a visual representation of site conditions. Moreover, the combined application of various innovative technologies allows visualization of the workplace in real time owing to the different functions of these technologies. Therefore, the growing implementation of BIM in the AEC industry is changing the way safety can be approached.

In this study, the objectives were to identify the applications and evolution of BIM for safety management in the subdomain of construction safety on scaffolding. It was evidenced that, despite the enormous evolution of the number of studies and technological innovations of BIM in construction safety, there is still a flagrant lack of knowledge and solutions for Identifying Hazards related to the subdomain of construction safety on scaffolding. Potential safety hazards can be automatically identified, and corresponding prevention methods can be applied using an automated approach. Moreover, its ease of utilization in worker safety training and education, design for safety, safety planning (job hazard analysis and pre-task planning), accident investigation, and facility and maintenance phase safety should be considered.

\section{References}

Akbarnezhad, A., K. C. G. Ong, and L. R. Chandra. 2014. "Economic and environmental assessment of deconstruction strategies using building information modeling". Automation in Construction 37 (january): 131-44. https://doi.org/10.1016/j.autcon.2013.10.017.

Akinci, B., M. Fischer, and J. Kunz. 2002. "Automated generation of work spaces required by construction activities". Journal of Construction Engineering and Management 128, no. 4 (july): 306-15. https://doi.org/10.1061/(ASCE)0733-9364(2002)128:4(306).

Bansal, V. K. 2011. "Application of geographic information systems in construction safety planning". International Journal of Project Management 29, no. 1 (january): 66-77. https://doi.org/10.1016/j.ijproman.2010.01.007.

Becerik-Gerber, B., F. Jazizadeh, N. Li, and G. Calis. 2012. "Application areas and data requirements for BIM-enabled facilities management". Journal of Construction Engineering and Management 138, no. 3 (march): 431-42. https://doi.org/10.1061/(ASCE)CO.19437862.0000433.

Booth, A., A. Sutton, and D. Papaioannou. 2016. Systematic approaches to a successful literature review. SAGE Publications Ltd.

Chau, K. W., M. Anson, and D. D. De Saram. 2005. "4D dynamic construction management and visualization software: 2. Site trial". Automation in Construction 14, no. 4 (august): 525-36. https://doi.org/10.1016/j.autcon.2004.11.005.

Chau, K. W., M. Anson, and J. P. Zhang. 2005. "4D dynamic construction management and visualization software: 1. Development". Automation in Construction 14, no. 4 (august): 512-24. https://doi.org/10.1016/j.autcon.2004.11.002.

Chavada, R., N. Dawood, and M. Kassem. 2012. "Construction workspace management: The development and application of a novel nD planning approach and tool". Electronic Journal 
of Information Technology in Construction 17 (september): 213-36. http://www.itcon.org/2012/13.

Cherneff, J., R. Logcher, and D. Sriram. 1991. "Integrating CAD with construction-schedule generation". Journal of Computing in Civil Engineering 5, no. 1 (january): 64-84. https://doi.org/10.1061/(ASCE)0887-3801(1991)5:1(64).

Chi, H., J. Chai, C. Wu, Zhu Junxiang, X. Wang, and Liu Chongyi. 2017. "Scaffolding progress monitoring of LNG plant maintenance project using BIM and image processing technologies". In 2017 International Conference on Research and Innovation in Information Systems (ICRIIS), 1-6. https://doi.org/10.1109/ICRIIS.2017.8002505.

Clayton, M. J., R. B. Warden, and T. W. Parker. 2002. "Virtual construction of architecture using 3D CAD and simulation". Automation in Construction 11, no. 2 (february): 227-35. https://doi.org/10.1016/S0926-5805(00)00100-X.

Clevenger, C., C. L. Del Puerto, and S. Glick. 2015. "Interactive BIM-enabled safety training piloted in construction education". Advances in Engineering Education 4, no. 3 (winter). https://eric.ed.gov/?id=EJ1076149.

"Council Directive 92/57/EEC". 1992. Official Journal of the European Communities L 245 / 6. https://eur-lex.europa.eu/eli/dir/1992/57/oj.

Cox, R. F., R. R. A. Issa, and D. Ahrens. 2003. "Management's perception of key performance indicators for construction". Journal of Construction Engineering and Management 129, no. 2 (march): 142-51. https://doi.org/10.1061/(ASCE)0733-9364(2003)129:2(142).

Dawood, N., E. Sriprasert, Z. Mallasi, and B. Hobbs. 2003. "Development of an integrated information resource base for 4D/VR construction processes simulation". Automation in Construction 12, no. 2 (march): 123-31. https://doi.org/10.1016/S0926-5805(02)00045-6.

Ding, L., Y. Zhou, and B. Akinci. 2014. "Building Information Modeling (BIM) application framework: The process of expanding from 3D to computable nD". Automation in Construction 46 (october): 82-93. https://doi.org/10.1016/j.autcon.2014.04.009.

Eadie, R., M. Browne, H. Odeyinka, C. McKeown, and S. McNiff. 2013. "BIM implementation throughout the UK construction project lifecycle: An analysis". Automation in Construction 36 (december): 145-51. https://doi.org/10.1016/j.autcon.2013.09.001.

Eastman, C., P. Teicholz, R. Sacks, and K. Liston. 2011. BIM Handbook: A guide to building information modeling for owners, managers, designers, engineers and contractors. $2^{\text {nd }}$ ed. John Wiley \& Sons.

Euler, J. K. 1994. "Advantages of using 3-D CAD plant models on the construction site". Computer-Aided Civil and Infrastructure Engineering 9, no. 6 (november): 435-44. https://doi.org/10.1111/j.1467-8667.1994.tb00349.x.

EUROSTAT. 2016. "European Statistical System Report 2016". https://ec.europa.eu/eurostat/web/products-statistical-books/-/KS-FN-17001 ? inheritRedirect=true.

Frijters, A. C. P., and P. H. J. J. Swuste. 2008. "Safety assessment in design and preparation $\begin{array}{lllll}\text { phase". Safety } \quad \text { Science } 46, \quad \text { no. } 2 \text { (february): } & 2 \text { 2 }\end{array}$ https://doi.org/10.1016/j.ssci.2007.06.032.

Gambatese, J., and J. Hinze. 1999. "Addressing construction worker safety in the design phase designing for construction worker safety". Automation in Construction 8, no. 6 (august): 643-49. https://doi.org/10.1016/S0926-5805(98)00109-5. 
Gibb, A., R. Haslam, D. Gyi, S. Hide, and R. Duff. 2006. "What causes accidents?". Proceedings of the Institution of Civil Engineers: Civil Engineering 159, no. 2 SPEC. ISS. (november): 4650. https://doi.org/10.1680/cien.2006.159.6.46.

$\mathrm{Gu}$, N., and K. London. 2010. "Understanding and facilitating BIM adoption in the AEC industry". Automation in Construction 19, no. 8 (december): 988-99. https://doi.org/10.1016/j.autcon.2010.09.002.

Guo, H. L., H. Li, and V. Li. 2013. "VP-based safety management in large-scale construction projects: A conceptual framework". Automation in Construction 34 (september): 16-24. https://doi.org/10.1016/j.autcon.2012.10.013.

Guo, Sy-Jye. 2001. "Integrating CAD and schedule for identification and resolution of work space conflicts between subcontractors". Canadian Journal of Civil Engineering 28, no. 5 (october): 759-68. https://doi.org/10.1139/cjce-28-5-759.

Hinze, J., and F. Wiegand. 1992. "Role of designers in construction worker safety". Journal of Construction Engineering and Management 118, no. 4 (december): 677-84. https://doi.org/10.1061/(ASCE)0733-9364(1992)118:4(677).

$\mathrm{Hu}, \mathrm{Z}$., and J. Zhang. 2011. "BIM- and 4D-based integrated solution of analysis and management for conflicts and structural safety problems during construction: 2 . Development and site trials". Automation in Construction 20, no. 2 (march): 155-66. https://doi.org/10.1016/j.autcon.2010.09.013.

ISO (International Organization for Standardization). 2010. Building information modelling Information delivery manual - Part 1: Methodology and format. ISO 29481-1:2010. http://www.iso.org/cms/render/live/en/sites/isoorg/contents/data/standard/04/55/455 01.html.

Jin, H., M. Nahangi, P. M. Goodrum, and Y. Yuan. 2017. "Model-based space planning for temporary structures using simulation-based multi-objective programming". Advanced Engineering Informatics 33 (august): 164-80. https://doi.org/10.1016/j.aei.2017.07.001.

Jung, Y., and G. E. Gibson Jr. 1999. "Planning for computer integrated construction". Journal of Computing in Civil Engineering 13, no. 4 (october): 217-25. https://doi.org/10.1061/(ASCE)0887-3801(1999)13:4(217).

Kang, J. H., S. D. Anderson, and M. J. Clayton. 2007. "Empirical study on the merit of webbased 4D visualization in collaborative construction planning and scheduling". Journal of Construction Engineering and Management 133, no. 6 (june): 447-61. https://doi.org/10.1061/(ASCE)0733-9364(2007)133:6(447).

Kartam, N. A. 1997. "Integrating safety and health performance into construction CPM". Journal of Construction Engineering and Management 123, no. 2 (june): 121-26. https://doi.org/10.1061/(ASCE)0733-9364(1997)123:2(121).

Kim, K., and J. Teizer. 2014. "Automatic design and planning of scaffolding systems using building information modeling". Advanced Engineering Informatics 28, no. 1 (january): 6680. https://doi.org/10.1016/j.aei.2013.12.002.

Kim, K., Y. Cho, and S. Zhang. 2016. "Integrating work sequences and temporary structures into safety planning: Automated scaffolding-related safety hazard identification and prevention in BIM". Automation in Construction 70 (october): 128-42. https://doi.org/10.1016/j.autcon.2016.06.012.

Kim, K., Y. Cho, and K. Kim. 2018. "BIM-Driven automated decision support system for safety planning of temporary structures". Journal of Construction Engineering and Management 
144, no. 8 (august): Article number 04018072. https://doi.org/10.1061/(ASCE)CO.19437862.0001519.

Koo, B., and M. Fischer. 2000. "Feasibility study of 4D CAD in commercial construction". Journal of Construction Engineering and Management 126, no. 4 (july): 251-60. https://doi.org/10.1061/(ASCE)0733-9364(2000)126:4(251).

Liberati, A., D. G. Altman, J. Tetzlaff, C. Mulrow, P. C. Gøtzsche, J. P. A. Ioannidis, M. Clarke, et al. 2009. "The PRISMA statement for reporting systematic reviews and meta-analyses of studies that evaluate health care interventions: Explanation and elaboration". PLoS Medicine 6, no. 7 (july): Article number e1000100. https://doi.org/10.1371/journal.pmed.1000100.

Martínez Aires, M. D., M. C. Rubio Gámez, and A. Gibb. 2010. "Prevention through design: The effect of European Directives on construction workplace accidents". Safety Science 48, no. 2 (february): 248-58. https://doi.org/10.1016/j.ssci.2009.09.004.

Martínez-Aires, M. D., M. López-Alonso, and M. Martínez-Rojas. 2018. "Building information modeling and safety management: A systematic review". Safety Science 101 (january): 1118. https://doi.org/10.1016/j.ssci.2017.08.015.

Mattila, M., M. Hyttinen, and E. Rantanen. 1994. "Effective supervisory behaviour and safety at the building site". International Journal of Industrial Ergonomics 13, no. 2 (april): 85-93. https://doi.org/10.1016/0169-8141(94)90075-2.

McKinney, K., J. Kim, M. Fischer, and C. Howard. 1996. "Interactive 4D-CAD". https://pdfs.semanticscholar.org/114a/ebe860a0a5a7275f945d0197220fc563217b.pdf?_ ga=2.94295325.1054056764.1570703018-703610335.1551191271.

McKinney, K., and M. Fischer. 1998. "Generating, evaluating and visualizing construction schedules with CAD tools". Automation in Construction 7, no. 6 (september): 433-47. https://doi.org/10.1016/S0926-5805(98)00053-3.

Melzner, J., S. Zhang, J. Teizer, and H. J. Bargstädt. 2013. "A case study on automated safety compliance checking to assist fall protection design and planning in building information models". Construction Management and Economics 31, no. 6 (june): 661-74. https://doi.org/10.1080/01446193.2013.780662.

Moon, H., N. Dawood, and L. Kang. 2014. "Development of workspace conflict visualization system using 4D object of work schedule". Advanced Engineering Informatics 28, no. 1 (january): 50-65. https://doi.org/10.1016/j.aei.2013.12.001.

Moon, H., H. Kim, C. Kim, and L. Kang. 2014. "Development of a schedule-workspace interference management system simultaneously considering the overlap level of parallel schedules and workspaces". Automation in Construction 39 (april): 93-105. https://doi.org/10.1016/j.autcon.2013.06.001.

Motamedi, A., and A. Hammad. 2009. "Lifecycle management of facilities components using radio frequency identification and building information model". Electronic Journal of Information Technology in Construction 14 (june): 238-62. https://www.itcon.org/paper/2009/18.

Park, C. S., and H. J. Kim. 2013. "A framework for construction safety management and visualization system". Automation in Construction 33 (august): 95-103. https://doi.org/10.1016/j.autcon.2012.09.012.

Porwal, A., and K. N. Hewage. 2013. "Building Information Modeling (BIM) partnering framework for public construction projects". Automation in Construction 31 (may): 204-14. https://doi.org/10.1016/j.autcon.2012.12.004. 
Qi, J., R. R. A. Issa, S. Olbina, and J. Hinze. 2014. "Use of building information modeling in design to prevent construction worker falls". Journal of Computing in Civil Engineering 28, no. 5 (september): Article number A4014008. https://doi.org/10.1061/(ASCE)CP.19435487.0000365.

Saurin, T. A., C. T. Formoso, and L. B. M. Guimarães. 2004. "Safety and production: An integrated planning and control model". Construction Management and Economics 22, no. 2: 159-69. https://doi.org/10.1080/0144619042000201367.

Seo, J., S. Han, S. Lee, and H. Kim. 2015. "Computer vision techniques for construction safety and health monitoring". Advanced Engineering Informatics 29, no. 2 (april): 239-51. https://doi.org/10.1016/j.aei.2015.02.001.

Shen, W., Q. Hao, H. Mak, J. Neelamkavil, H. Xie, J. Dickinson, R. Thomas, A. Pardasani, and H. Xue. 2010. "Systems integration and collaboration in architecture, engineering, construction, and facilities management: A review". Advanced Engineering Informatics 24, no. 2 (april): 196-207. https://doi.org/10.1016/j.aei.2009.09.001.

Shou, W., J. Wang, X. Wang, and H. Y. Chong. 2015. "A comparative review of building information modelling implementation in building and infrastructure industries". Archives of Computational Methods in Engineering 22, no. 2 (april): 291-308. https://doi.org/10.1007/s11831-014-9125-9.

Silva, M. J. F., F. Salvado, P. Couto, and A. Vale e Azevedo. 2016. "Roadmap proposal for implementing building information modelling (BIM) in Portugal". Open Journal of Civil Engineering 6, no. 03 (june): 475-81. https://doi.org/10.4236/ojce.2016.63040.

Succar, B. 2009. "Building Information Modelling framework: A research and delivery foundation for industry stakeholders". Automation in Construction 18, no. 3 (may): 357-75. https://doi.org/10.1016/j.autcon.2008.10.003.

Succar, B., and M. Kassem. 2015. "Macro-BIM adoption: Conceptual structures". Automation in Construction 57 (september): 64-79. https://doi.org/10.1016/j.autcon.2015.04.018.

Suermann, P. C., and R. R. A. Issa. 2009. "Evaluating industry perceptions of building information modeling (BIM) impact on construction". Electronic Journal of Information Technology in Construction 14 (august): 574-94. https://www.itcon.org/paper/2009/37.

Sulankivi, K., T. Mäkelä, and M. Kiviniemi. 2009. "BIM-based site layout and safety planning". VTT Symposium (Valtion Teknillinen Tutkimuskeskus) no. 259: 125-40.

Tatum, S. A., J. C. Byrum, and P. W. Rourke. 1994. "Design validation using computer models in lieu of full-scale mockups". Marine Technology and SNAME News 31, no. 3 (july): 225-30.

Teizer, J., B. S. Allread, C. E. Fullerton, and J. Hinze. 2010. "Autonomous pro-active real-time construction worker and equipment operator proximity safety alert system". Automation in Construction 19, no. 5 (august): 630-40. https://doi.org/10.1016/j.autcon.2010.02.009.

Trebbe, M., T. Hartmann, and A. Dorée. 2015. "4D CAD models to support the coordination of construction activities between contractors". Automation in Construction 49, PA (january): 83-91. https://doi.org/10.1016/j.autcon.2014.10.002.

Tse, T. C. K., K. D. A. Wong, and K. W. F. Wong. 2005. "The utilisation of Building Information Models in nD modelling: A study of data interfacing and adoption barriers". Electronic Journal of Information Technology in Construction 10: 85-110. http://www.itcon.org/2005/8. 
Volk, R., J. Stengel, and F. Schultmann. 2014. "Building Information Modeling (BIM) for existing buildings - Literature review and future needs". Automation in Construction 38 (march): 109-27. https://doi.org/10.1016/j.autcon.2013.10.023.

Waly, A. F., and W. Y. Thabet. 2003. "A virtual construction environment for preconstruction planning". Automation in Construction 12, no. 2 (march): 139-54. https://doi.org/10.1016/S0926-5805(02)00047-X.

Wang, H. J., J. P. Zhang, K. W. Chau, and M. Anson. 2004. "4D dynamic management for construction planning and resource utilization". Automation in Construction 13, no. 5 SPEC. ISS. (september): 575-89. https://doi.org/10.1016/j.autcon.2004.04.003.

Wang, W. C., J. J. Liu, and S. C. Chou. 2006. "Simulation-based safety evaluation model integrated with network schedule". Automation in Construction 15, no. 3 (may): 341-54. https://doi.org/10.1016/j.autcon.2005.06.015.

Wang, X., and H. Y. Chong. 2015. "Setting new trends of integrated Building Information Modelling (BIM) for construction industry". Construction Innovation 15, no. 1 (january): 26. https://doi.org/10.1108/Cl-10-2014-0049.

Wang, J., H. Chi, C. Liu, and X. Wang. 2016. "BIM-enabled collaborative scaffolding scoping and design". In Cooperative Design, Visualization, and Engineering, edited by Yuhua Luo, 4350. Lecture Notes in Computer Science. Springer International Publishing.

Yamazaki, Y. 1992. "Integrated design and construction planning system for computer integrated construction". In Computer Integrated Construction, edited by Harry Wagter, 145-52. Amsterdam: Elsevier. https://doi.org/10.1016/B978-0-444-89262-1.50021-X.

Zhang, S., J. Teizer, J. K. Lee, C. M. Eastman, and M. Venugopal. 2013. "Building Information Modeling (BIM) and safety: Automatic safety checking of construction models and schedules". Automation in Construction 29 (january): 183-95. https://doi.org/10.1016/j.autcon.2012.05.006.

Zhang, S., F. Boukamp, and J. Teizer. 2015. "Ontology-based semantic modeling of construction safety knowledge: Towards automated safety planning for job hazard analysis (JHA)". Automation in Construction 52 (april): $29-41$. https://doi.org/10.1016/j.autcon.2015.02.005.

Zhou, W., J. Whyte, and R. Sacks. 2012. "Construction safety and digital design: A review". $\begin{array}{llll}\text { Automation in } & \text { Construction } & 22 & \text { (march): }\end{array}$ https://doi.org/10.1016/j.autcon.2011.07.005.

Zhou, Y., L. Ding, X. Wang, M. Truijens, and H. Luo. 2015. "Applicability of 4D modeling for resource allocation in mega liquefied natural gas plant construction". Automation in Construction 50, no. C (february): 50-63. https://doi.org/10.1016/j.autcon.2014.10.016. 